\title{
LITERATURE REVIEW ON SPECIFIC TYPES OF RISK FACED BY FIRMS
}

\author{
RUI BRITO \& CELESTE JACINTO \\ UNIDEMI, Department of Mechanical and Industrial Engineering, NOVA School of Science and Technology, \\ Universidade NOVA de Lisboa, Portugal
}

\begin{abstract}
This contribution presents a literature review focused on four types of risk that firms may face during their operation, namely, operational risk, supply chain risk, strategic risk, and enterprise risk. The applied methodology consisted of an online search of databases regarding scientific documents in English, published in different journals; the search was based on several keywords/strings (themes) that had to be included just as in the article title. The number of surveyed papers by theme showed a variation from 40 to 600 and the number of citations of those papers showed a wider variation from 2 to 918. Selected articles from the four themes were analyzed and the first five with more citations were read in full to make a synopsis of each article. However, to reduce the length of the current paper, only two synopses of each theme were explicitly included here. Overall, the findings show that firm's risks are an important subject for academic researchers, managers and stakeholders, for risky situations can occur and sometimes lead to very heavy losses. A few research gaps were identified, either the lack of quantitative models for the assessment and management of enterprises' risks, or insufficient practical support/expertise, namely through case studies and/or well-designed surveys. The review ends with the limitations and contributions of the study.
\end{abstract}

Keywords: risk management, business continuity management, operational risk, supply chain risk, strategic risk, enterprise risk.

\section{INTRODUCTION}

The world's economic development is supported by a growing system of interconnected firms which are interdependent and face diverse risks, namely operational risk, supply chain risk, strategic risk, and enterprise risk, that can jeopardize their activity and deter the achievement of their objectives.

Risks are becoming increasingly important and damages can actually happen [1], such as the 4 million laptop batteries manufactured by Sony that were recalled by Dell due to a fire hazard in 2006, or the 1,400 employees laid off by Land Rover following a supplier becoming insolvent in 2001, or the Dole revenue loss due to the destruction of banana plantations by a hurricane in 1998, or the 400 million Euros loss by Ericsson originated by a fire in a plant of a semiconductor supplier in 2000. Additionally, Volvo Car presented, in June 2008, a 28\% revenue decrease, in comparison with the same period of 2007, for US dollar weakness, and the earthquake suffered by Taiwan in 2006 that damaged underwater cables, and slowed down communications implying higher waiting time of containers in the port of Shanghai [2]. Thus, it becomes apparent that risk management and the overall business continuity management needs to be addressed.

The scope of this paper embraces not only the characterization and review of four distinctive types of risk, but also a brief discussion on business continuity management, which is a proactive management approach for risk treatment and prevention.

The objective of this study is to present a review not only on firm's risks from a broad perspective, i.e., all types of risk directly associated with top management and governance of a firm, but also on how to prevent and address business hazards, to ensure business continuity. The selection of risks is based on what may arise from top level managerial decisions, but 
not considering low level management decisions or less significant risks, such as the ones related to inventory or warehousing management.

\subsection{Risk management}

According to the International Standard ISO 31000 [3], risk is an "effect of uncertainty on objectives" (paragraph 3.1) and risk management is the "coordinated activities to direct and control an organization with regard to risk" (paragraph 3.2), being these activities part of the overall functioning of the firm, including governance and leadership. To achieve the firm's objectives, risk management shall consider principles, framework and process as its main components.

The aim of risk management is to create value and to protect it through several principles, namely by continual improvement through learning and experience, integration of risk management within all firm's activities, best available information both existing and foreseen, human and cultural factors due to their relevant impact, etc., which drive better performance and foster innovation, allowing the firm to accomplish its objectives.

The purpose of any risk management framework [3], with support and commitment of top management, is enabling the firm's organization to incorporate risk management in each and every activities and functions, through design, which comprises understanding the context (external and internal), implementation with the commitment and follow-up of stakeholders, evaluation through regular measurements, and improvement in an effective and efficient way, and, finally, integration of this evolving and repeated process, as a virtuous cycle.

Risk management, thus, is a systematic and continuous process, that implies the application of policies, procedures and practices to vital activities such as communication and consultation to support stakeholders, or establishing the context (internal and external) to customize the process of risk management, as well as assessing, treating, monitoring, reviewing, recording and reporting risk [3]. All these functions, together, are essential for an efficient management of risk.

\subsection{Business continuity management}

Business continuity management (BCM) is defined, as quoted in Cornish [4], as "a holistic management process that identifies potential threats to an organization and the impact to business operations that those threats, if realized, might cause, and which provides a framework for building organizational resilience with the capability for an effective response that safeguards the interests of its key stakeholders, reputation, brand and value-creating activities". To manage the diverse challenges set by unexpected events, it is advisable that a firm creates an organizational structure centered on the business continuity manager, reporting to a crisis management team (CMT) and supported by damage assessment and salvage team, IT recovery team, communications recovery team, and support team [5]. Therefore, this is a framework that is intended to deal with risk and prevent its negative impacts on businesses.

This approach means an integrated view starting with some preparation before any undesirable event occurs, i.e., pre-event preparation, including risk assessment and impact analysis, as well as training on a continuous basis [5]. The next step regards the event itself implying adequate response together with risk mitigation and correct information management not only inside the firm (employees and outer intervening teams) but also outside the firm (public in general and stakeholders). The final step is the post-event that 
concerns the restoration of current activity that sometimes is below its normal level, and additionally taking the necessary lessons to be better prepared for a similar event in the future.

To be effective and efficient BCM shall be used as a management system through a PDCA cycle (plan, do, check, and act) requiring continuous improvement that, quoting Cornish [4], can be translated by a lifecycle: (i) comprehending the organization; (ii) defining BCM strategy; (iii) evolving and deploying $\mathrm{BCM}$ responses; and (iv) training, maintaining and reexamining BCM arrangements.

The next subsections present a brief summary of risk classification (or types of risk), especially those commonly associated with business (dis)continuity. These are the four risk types that were included in the scope of the current literature review.

\subsection{Operational risk}

The global financial meltdown that occurred in 2008 was charged to greed of bankers and failure of regulation. However, one could argue that it has been a failure of the operational risk management (ORM). Financial institutions (e.g., banks, hedge funds, etc.) did not understand and properly deal with both the risk of leverage of unusual financial instruments and the failure of debt payments; moreover, they had not enough provisions to secure the risk [6]. The safety protection of regulation governance did not work but were not the financial institutions that placed the world's economy on the route to the great disaster.

It is quite common to accept that the operational risk is only important for financial industry, such as banks, investment funds, etc., but all organizations can face it owing to failure of people, e.g., a manager underestimates the complexity and time for completion of a project, or to failure of equipment, for instance a computer system breakdown [7].

The Second Basel Accord, quoted in Robinson [7], defines operational risk as "the risk of loss resulting from inadequate or failed internal processes, people and systems or from external events" and the scope of ORM, which is distinct from market risk and credit or trade risk, restrains itself to the management of some elements, such as: (i) process; (ii) people; (iii) insurance; (iv) supply chain and outsourcing; (v) infrastructure, systems and telecommunications; and (vi) physical and information security [7].

The causes of disruption, also known as threats or hazards, always come from beyond current operational control and include natural events (e.g., a lightning bolt, etc.), or human actions (i.e., errors, mistakes, sabotage, etc.). Thus, it is crucial to know in advance the exposure to risk, considered as the combination of two major elements of risk: (i) loss, as the reflection of pain or loss or discomfort provoked by an event; and (ii) probability, as a qualitative indicator of likelihood or a suggestion of potential frequency of happening such event. Furthermore, the firm's risk profile shall also be defined by three components: (i) threat profile, indicating the hazards importance; (ii) loss profile, demonstrating how it feels the event aftermath; and (iii) gap profile, showing the holes or overlaps of its defences [7].

When performing risk assessment [5] the analyst should calculate the risk priority number (RPN) which is equal to severity $\mathrm{x}$ likelihood (or occurrence) $\mathrm{x}$ non-detectability, as part of the failure modes and effects analysis (FMEA).

\subsection{Supply chain risk}

Shorter product lifecycle (PLC) and higher demand, together with increased importance of lead time and price levels, in a more competitive world, make supply chains more complex [2]. Unexpected material or financial or information risks can originate problems and sometimes disruptions associated with delays and recovery actions. 
In a globalized world, involving many countries, supply chain risks are higher as compared to a single country, owing to many connections between diversified networks of different forms [8] and those risks include demand risks (e.g., demand uncertainty, forecast inaccuracies, etc.), supply risks (taking advantage by supplier, quality of inward product, etc.), operational risks (e.g., safety, inventory possession, etc.), which influence each other, and other risks not directly controlled by the firm (e.g., security, or currency exchange rates).

Supply risks classification and methodologies are diverse and frequently they are simply centered on disruptive events of forecasting, rather than on the origin causes of uncertainties. Often the analysis concerns only discrete disruptive events (e.g., supplier bankruptcy or natural cataclysm) and not uninterrupted modifications of the firm's context (i.e., strategic options of suppliers or expectations of customers) which means a very short-term approach [9]. Thus, supply chain risk shall also be widely scrutinized through assessment of supplier capabilities and supply chain structure for anticipating disruptions allowing evaluation of mitigation and response actions.

Supply chains face diverse risks, such as disruption, delays, systems, forecast, intellectual property, procurement, receivables, inventory, and capacity [10] that, in accordance with these authors, but excluding systems' risks and intellectual property risks, can be managed through mitigation strategies, namely adding capacity, adding inventory, having redundant suppliers, increasing responsiveness, increasing flexibility, aggregating or pooling demand, increasing capability, and having more customer accounts. Furthermore, to manage positively disruption risks firms shall combine risk assessment with risk mitigation, defining strategies and actions to minimize rate and impact of faced risks together with increase of sustainability/absorption capacity of supply chain participants [11]. This can be accomplished through new systems for evaluating and managing the operational risks with the engagement of the board of directors.

\subsection{Strategic risk}

Strategic risk can exist in accounting auditing considering that the quality level of accounting systems, and self-controls of firms, as well as the rate and intricate of transactions of firm, can lead to better understanding of which accounts are more prone to misstatements [12]. However, reporting managers can anticipate this common assumption and, as an example, allocate additionally expenses to fixed assets accounting, in the assumption that auditors shall not pay so much attention to it for they shall not present any intricate transactions.

Firms usually cooperate, which means a peaceful relationship, since that short-term benefits, potentially resulting from a sudden offensive action, can be lost by medium- or longterm costs owing to conflicts created [13]. Furthermore, inducements for cooperation exist if severe penalties can be applied. However, under strategic risk the cooperation sustainability is diminished due to the alignment of predatory (meaning an attack to a peaceful player up to then) and pre-emptive (meaning an attack to prevent a strike without warning) motives [13].

Strategic risk assessment is usually performed by the firm's top management team (TMT) together with related risk-taking decisions. So, the chief executive officer (CEO) point of view is a key issue in this decision process, which is influenced by his/her personal values and preferences [14]. However, it shall also be taken into consideration the demographic profile of the other hierarchy levels, due to their indirect influence on firm's information analysis and actions.

Risk propensity has been traditionally understood as a characteristic of individuals but nowadays it has also been considered as of firms [15]. Consequently, strategic risk behavior 
is modified by three sets of factors: (i) characteristics of decision makers; (ii) firm environment; and (iii) characteristics of the situation to be addressed. Considering that for a firm in need of internal growth, risk-taking is more relevant and dependent on marketing decisions (markets and products), risk-taking propensity shall consider marketing structure, operation and control.

In a study by Lim and McCann [16], the authors show that firm managers are less risk tolerant when compared with shareholders, and that a solid board of directors can strongly counteract this behavior, which may present a higher efficiency if directors get inducements to comply with shareholder interests. This can be accomplished by granting firm shares to directors [16].

\subsection{Enterprise risk}

The enterprise risk management (ERM) may be defined as "a process, effected by an entity's Board of Directors, management and other professionals, applied in strategy setting and across the enterprise, designed to identify events that may affect the entity, and manage risk to be within its risk appetite, to provide reasonable assurance regarding the achievement of entity objectives" [17]. According to Hiles [17], the ERM framework proposed by the Committee of Sponsoring Organizations (COSO) with the purpose of meeting firms' objectives, considers four risk categories: (i) strategic, from top level goals; (ii) operations, from resources deployment; (iii) reporting, from trustworthy of reports; and (iv) compliance, from application of legislation.

Although ERM provides relevant support, it still presents limitations for it is dependent of human decisions, and so, some inadequate decisions can be made [17] In this perspective, it can be useful to have a defined organization for ERM that reports to Vice President and Chief Risk Officer, and includes namely ERM Director, Insurance Risk Manager, Corporate Credit Manager, and ERM Managers, although it is not as common as it happens with marketing, sales and procurement departments or eventually with accounting or health and safety departments [18].

The regular activity of a firm faces several risks, such as credit, market, operational, liquidity, legal, strategic, reputational, and business, being prudent to use a wide approach to risk management [19]. Starting with a disaster recovery planning (DRP) concerning recoup of IT and communications power, passing to BCP regarding assurance of continuous viability and operation of firm, up to crisis management planning (CMP) for dealing with abnormal conditions, such as product recall or hostage, firms can additionally consider health and safety, environmental protection, security and insurance. This gradual risk coverage is converging to a total asset protection (TAP), as called by Hiles [19].

Another concept, proposed by Hiles [19], is marketing protection (MP) that takes another risk approach. The traditional perspective of risk considers the effect on firm both in cash and in non-cash terms, through auditing, e.g., loss of market share, loss of product and cost of fines together with loss of image and regulatory non-compliance. The MP considers the whole value of the business from a marketing point of view and uses techniques of advertising and of brand management to assess the potential loss and to justify the reasonable spending on $\mathrm{BCP}$.

\section{METHODOLOGY FOR THE REVIEW OF LITERARURE}

The methodology applied in this work consisted of a literature review using, as far as possible, a systematic approach (Fig. 1), in accordance with the procedure followed by Torreglosa et al. in 2016 [20]. 


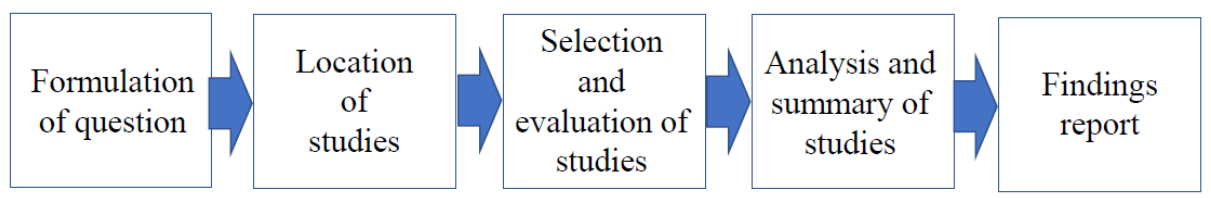

Figure 1: Steps followed in a systematic literature review. (Source: Adapted from Torreglosa et al. [20].)

The research started with the formulation of the central question, which is related to potential risks faced by firms and on how to prevent and address their consequences. This was followed by an online search of databases concerning scientific articles in English language, e.g., Elsevier, Springer, Emerald, Wiley, Taylor and Francis, but excluding books except if edited, using search engines such as B-on and Google Scholar. The second step regarded the search period between 2008 and 2018 with documents sorted by relevance and using the following key words and/or strings: "operational risk", "supply chain risk", "strategic risk", and "enterprise risk", which should be included "just as" in the document title. This required condition, from the point of view of the authors, may indicate that researchers, quoting the concerned key words/strings just as in the article's title, possibly consider them as deserving to be more noticeable than the other keywords. Due to time restrictions, the purpose was to collect between twenty to thirty studies considered relevant within the key words/strings specified for each theme.

The third step involved reading the abstracts of the previously collected studies for assessing their relevance within this work, as well as excluding all documents published in non-academic collections, being the remaining downloaded. The fourth step consisted of the reading and analysis of the five most cited articles of the remaining documents that were retrieved from each of the four strings mentioned before (operational risk, supply chain risk, strategic risk, and enterprise risk). After a closer examination of these twenty articles, they were assigned to the different themes (each theme matching a specific search string). Finally, the "reporting" step, produced an organized output, by theme, showing authorship, citation volume, and a synopsis of the twenty selected studies.

\section{RESULTS AND DISCUSSION}

\subsection{Results}

Using the four strings mentioned above and aiming to identify between twenty to thirty articles for each of the four strings that were present just as in the title of the document, the number of surveyed documents (Table 1) were approximately between forty to one hundred titles for each theme, with the exception of "strategic risk", which returned several hundreds.

Table 1: Number of papers surveyed by theme.

\begin{tabular}{|l|c|}
\hline Theme & $\begin{array}{c}\text { Surveyed potential candidates } \\
\text { (approximate number) }\end{array}$ \\
\hline Operational risk & 60 \\
\hline Supply chain risk & 60 \\
\hline Strategic risk & 600 \\
\hline Enterprise risk & 40 \\
\hline
\end{tabular}


The next step leads to a shorter list (Table 2) following a preliminary evaluation to exclude articles unrelated, directly or indirectly, to firms. As already explained, this new scrutiny was based on the exclusion criteria, namely, abstract contents and publication in non-academic collections.

Table 2: Number of papers selected.

\begin{tabular}{|l|c|c|}
\hline Theme & Retrieved & Number of citations \\
\hline Operational risk & 24 & From 29 up to 297 \\
\hline Supply chain risk & 31 & From 52 up to 918 \\
\hline Strategic risk & 20 & From 5 up to 100 \\
\hline Enterprise risk & 22 & From 2 up to 639 \\
\hline
\end{tabular}

From the above pre-selected articles only two of the five "most cited" of each theme, which was the criterion established for relevance, were summarized for inclusion in this review (Tables 3-6) with mention to authors, year of publication, number of citations and a synopsis of their contents.

It shall be noted that the "strategic risk" theme needed a more extensive survey $(\sim 600$ articles) in order to reach the minimum quantity of selected articles (20), for assuring compliance with the just as condition established from the beginning. The remaining three groups needed only the scrutiny of a maximum of 60 and a minimum of 40 articles.

The "strategic risk" theme, found in larger quantities but having lower rates in terms of standing out in the article's title, may suggest, to some extent, that it is more generic than the remaining three categories, resulting from a higher dispersion and variability within the specialty literature.

As Table 2 shows the articles with less citations were found in the themes "enterprise risk" $(n=2)$ and "strategic risk" $(n=5)$, while the most cited, by far, were found within the themes "enterprise risk" again $(\mathrm{n}=639)$ and "supply chain risk" $(\mathrm{n}=918)$.

It should be noted, however, that the criterion adopted here (i.e., the most cited) may hide a serious limitation, since the most recent studies may have a "high citation potential", but the time span is still short to allow assessing their citation volume. Only the future will tell if some relevant articles had been wrongly dismissed in the present review. In any case, reviewing all the papers selected (Table 2) would represent a disproportionate burden and the criterion adopted, based on the volume of citations received, seemed appropriate even if it may not guarantee full inclusion of relevance.

The summary Tables 3-6 for two (out of the five) selected articles of each theme are presented hereafter. They illustrate and exemplify how the whole study was carried out. The citations counting refers to April and May 2019.

\subsection{Discussion}

This summarized review shows that the approach used by researchers in this domain has been different for each theme, suggesting the actual diversity of each one. The synopsis included in Tables 3-6 give a glimpse of the focus of each study, as well as their main contributions. From the results obtained in this review, despite its limitations, it becomes apparent that the supply chain risk was more studied through semi-quantitative models owing to the availability of more quantified data and related algorithms, and the operational risk has 
Table 3: Operational risk.

\begin{tabular}{|l|l|l|}
\hline Author(s) & Cit. & Synopsis \\
\hline Michalski [21] & 297 & $\begin{array}{l}\text { This study introduces the effects on firm value through } \\
\text { inventory management of a focal firm by operating risk } \\
\text { originated by delivery out of schedule risk of suppliers and } \\
\text { proposes a method for supplier selection based on portfolio } \\
\text { management theory. Since maximization of enterprise value is } \\
\text { carried out centered on risk and uncertainty, findings show that } \\
\text { using two suppliers (A better and B worse) focal firm can } \\
\text { achieve benefits. }\end{array}$ \\
\hline Michalski [22] 280 & $\begin{array}{l}\text { Describes the outcomes of operating risk for the firm's value, } \\
\text { arising from purchasers with accepted postponement payment } \\
\text { policy, and suggests a model supported by the portfolio } \\
\text { management theory allowing the amount of receivable } \\
\text { accounts, considering the changes on firm value. The portfolio } \\
\text { perspective of the management of accounts receivable } \\
\text { considers the rate of profit (rate of advantage from assets) as a } \\
\text { key criteria to foster purchaser decisions, being the group of } \\
\text { customers willing to get trade credit an high risk group which } \\
\text { may be considered as another of the several groups of firm } \\
\text { customers that may become profitable. }\end{array}$ \\
\hline
\end{tabular}

Table 4: Supply chain risk.

\begin{tabular}{|l|l|l|}
\hline Author(s) & Cit. & Synopsis \\
\hline $\begin{array}{l}\text { Manuj and } \\
\text { Mentzer [8] }\end{array}$ & 918 & $\begin{array}{l}\text { The authors propose a model of global supply chain risk } \\
\text { management strategies (postponement, speculation, hedging, } \\
\text { control/share/transfer, security, and avoidance) and the role of } \\
\text { three moderators (team composition, complexity of the supply } \\
\text { chain, and the degree of inter-organizational learning), } \\
\text { allowing managers to evaluate which is more suitable to each } \\
\text { global supply chain. Suggestions for future research include } \\
\text { the link between strategies and outcomes, and the inclusion of } \\
\text { other industries and firms. }\end{array}$ \\
\hline $\begin{array}{l}\text { Tang and } \\
\text { Tomlin [1] }\end{array}$ & $\begin{array}{l}\text { Present a coherent whole framework and five distinctive } \\
\text { models for addressing flexibility (flexible supply either via } \\
\text { multiple suppliers or via flexible supply contracts, flexible } \\
\text { process, flexible product, and flexible pricing) in order to } \\
\text { achieve relevant strategic value through fulfilling a program } \\
\text { for risk reduction without investing in high degree of } \\
\text { flexibility. For future research they suggest studying the mix } \\
\text { of distinct flexibility strategies. }\end{array}$ \\
\hline
\end{tabular}


Table 5: Strategic risk.

\begin{tabular}{|l|l|l|}
\hline Author(s) & Cit. & $\begin{array}{l}\text { Synopsis } \\
\text { Chassang and } \\
\text { Miquel [13] }\end{array}$ \\
\hline 100 & $\begin{array}{l}\text { Explore the functioning of cooperation with and without } \\
\text { strategic risk that can be used for nonviolent conflicts, e.g., } \\
\text { price wars between firms. Results demonstrate that when both } \\
\text { players held complete information, peace maintenance relies } \\
\text { exclusively on predatory potential gains of opponents, but } \\
\text { when players have distinct information concerning their } \\
\text { context there is a strategic risk, and maintenance of peace } \\
\text { relies not only on predatory but also on preemptive potential } \\
\text { gains. Future research may focus on better comprehension of } \\
\text { conflict and peace factors. }\end{array}$ \\
\hline $\begin{array}{l}\text { Kish-Gephart } \\
\text { and Campbell }\end{array}$ & 72 & $\begin{array}{l}\text { Present the effect of perceived social class origins of chief } \\
\text { executive officers (CEO) on decision-making concerning } \\
\text { firm's risk, as well as moderating effects of other relevant } \\
\text { early professional experiences, namely elite education and } \\
\text { various managerial training. Results show that CEOs with } \\
\text { upper class background are more prone to take higher levels of } \\
\text { strategic risks followed by those from lower class, while elite } \\
\text { education diminish propensity of CEOs with lower class } \\
\text { origins to engage in risk taking, and general managerial } \\
\text { training augments the trend to engage in risk taking for both } \\
\text { lower social class origins and upper social class origins. }\end{array}$ \\
\hline
\end{tabular}

Table 6: Enterprise risk.

\begin{tabular}{|l|l|l|}
\hline Author(s) & Cit. & Synopsis \\
\hline $\begin{array}{l}\text { Hoyt and } \\
\text { Liebenberg [23] }\end{array}$ & $639 \begin{array}{l}\text { Study the importance of enterprise risk management (ERM) } \\
\text { and the size of ERM programs implemented in U.S. public } \\
\text { traded insurance firms. Findings indicate ERM increase firm } \\
\text { value; average user of ERM is bigger and holds lower degree } \\
\text { of leverage, opacity, financial slack, and return volatility than } \\
\text { the average non-user. Furthermore, average ERM user has } \\
\text { lower dependency on reinsurance as compared to nonusers } \\
\text { and the median change in value is bigger for ERM than for } \\
\text { nonusers. Future research may include wider samples and } \\
\text { additional ERM measures. }\end{array}$ \\
\hline $\begin{array}{l}\text { Gordon et al. } \\
\text { [24] }\end{array}$ & $\begin{array}{l}\text { Investigate whether the relationship between ERM and firm } \\
\text { performance is dependent on some factors, proposing a model } \\
\text { that considers five major factors (context uncertainty, } \\
\text { competition within industry, dimension of firm, diversity of } \\
\text { firm transactions, and actual action of top management team } \\
\text { (TMT) monitoring). Results confirmed model robustness and } \\
\text { suggested ERM Index (ERMI) is acceptable for measurement } \\
\text { of ERM efficacy. For additional research they mentioned } \\
\text { other contingency factors and other performance indicators. }\end{array}$ \\
\hline
\end{tabular}


been more concerned with financial implications, since management is mainly centered on outcomes of firm's activities translated in monetary units. Additionally, the strategic risk, in accordance with its name, addresses risk from a top level or wholly perspective, while the enterprise risk is more concerned with firm's performance and its overall lean functioning.

\section{CONCLUDING REMARKS}

This review addressed four themes regarding business risks and their management by firms, showing clear differences in publication volumes concerning each theme, giving evidence that some risks have received more attention from the research community, while others are still less explored by the literature. From the 20 studies reviewed in detail, which were selected for having relevance and significance within this broad topic, it appears that a few research gaps had been identified, namely the need to develop quantitative models for the assessment and management of enterprises' risks, i.e., all types of risk directly associated with top management governance in a firm. Alongside risk assessment models, the literature also reveals lack of practical support/expertise, namely through case studies and/or welldesigned surveys. Such practice-oriented research would help identifying best practice and more efficient risk treatment strategies.

In the authors' opinion, all the risks addressed in this work and others not included here, such as project management, facilities management, etc., suggest that risk management by firms can be viewed under different dimensions, as it happens with product quality that, according to Garvin [25], presents eight dimensions (performance, features, reliability, conformance, durability, serviceability, aesthetics, and perceived quality). In the case of risk management, the dimensions serviceability and aesthetics could possibly be discarded; by contrast the dimensions performance and reliability are of utmost importance for the success of an enterprise.

Lastly, the many risks faced and managed by firms, which are sometimes interconnected and partially overlapped, e.g., supply chain risk and operational risk, or enterprise risk and strategic risk, can perhaps be aggregated into one embracing title, such as "business risk", which can be considered as the ultimate risk that derived from decisions of firm's chief officers (operations, marketing, information, financial, etc.), all of which, if not duly addressed, may jeopardize the firm's activity and lead irreversibly to disruption and the closing of the firm.

\subsection{Limitations}

In addition to the limitations resulting from the broad scope, i.e., the variety of selected risks and the relatively low number of scrutinized articles by theme, this review presents other limitations worth mentioning.

The inclusion criteria have their own limitations, namely, (1) only the titles were searched in the first round; (2) the key words used (or strings) should appear just as in the article's title; and (3) within each theme, only the five "most cited" were selected for inclusion in the analysis. However, this rather restrictive approach intended to achieve two objectives. Firstly, to segregate the articles that, although dealing with the related theme, did not highlight it as the most relevant when compared to the other key words/strings. Secondly, the most cited implied that the retrieved articles are relevant due to the number of registered citations.

Furthermore, this criterion (number of cites), considered as an important indicator of article's impact [26], has important limitations, for not including other criteria, i.e., categories and sub-categories, such as distinct periods of the time span with different minimum number of citations [26] used in distinct reviews (critical, systematic, etc.) [27], but it was feasible 
within the time span available; at least it is objective, countable, and reveals which studies have been emphasized by others.

\subsection{Contributions}

This study provides a critical reflection on the broad concept of risk management addressed by researchers, pointing out some types of risk that may deserve further understanding, together with a closer approach to managerial practices in order to support the development of new theoretical frameworks and models that can contribute to guide practitioners in improving firm's management and its performance.

\section{ACKNOWLEDGEMENT}

The authors acknowledge Fundação para a Ciência e a Tecnologia (FCT-MCTES) for its financial support via the project UIDB/00667/2020 (UNIDEMI).

\section{REFERENCES}

[1] Tang, C. \& Tomlin, B., The power of flexibility for mitigating supply chain risks. International Journal of Production Economics, 116(1), pp. 12-27, 2008.

[2] Tang, O. \& Musa, N., Identifying risk issues and research advancements in supply chain risk management. International Journal of Production Economics, 133(1), pp. 25-34, 2011.

[3] ISO 31000, Risk Management: Guidelines, International Organization for Standardization: Geneva, Switzerland, p. 7, 2018.

[4] Cornish, M., Business continuity management methodology. The Definitive Handbook of Business Continuity Management, 3rd ed., ed. A. Hiles, John Wiley and Sons: Chichester, pp. 121-126, 2011.

[5] Tammineedi, R.L., Business continuity management: A standards-based approach. Information Security Journal: A Global Perspective, 19, pp. 36-50, 2010.

[6] Viner, P., Operational risk management: Risk and consequences. The Definitive Handbook of Business Continuity Management, 3rd ed., ed. A. Hiles, John Wiley and Sons: Chichester, p. 74, 2011.

[7] Robinson, J., Operational risk management: A primer. The Definitive Handbook of Business Continuity Management, 3rd ed., ed. A. Hiles, John Wiley and Sons: Chichester, pp. 66-70, 2011.

[8] Manuj, I. \& Mentzer, J.T., Global supply chain risk management strategies. International Journal of Physical Distribution and Logistics Management, 38(3), pp. 192-223, 2008.

[9] Trkman, P. \& McCormack, K., Supply chain risk in turbulent environments: A conceptual model for managing supply chain network risk. International Journal of Production Economics, 19(2), pp. 247-258, 2009.

[10] Chopra, S. \& Sodhi, M.S., Managing risk to avoid supply-chain breakdown. Sloan Management Review, 46(1), pp. 53-61, 2004.

[11] Kleindorfer, P.R. \& Saad, G.H., Managing disruption risks in supply chains. Production and Operations Management, 14(1), pp. 53-68, 2005.

[12] Bowlin, K., Risk-based auditing, strategic prompts, and auditor sensitivity to the strategic risk of fraud. The Accounting Review, 86(4), pp. 1231-1253, 2011.

[13] Chassang, S. \& Miquel, G.P., Conflict and deterrence under strategic risk. The Quarterly Journal of Economics, 125(4), pp. 1821-1858, 2010. 
[14] Kish-Gephart, J. \& Campbell, J.T., You don't forget your roots: The influence of CEO social class background on strategic risk taking. Academy of Management Journal, 58(6), pp. 1614-1636, 2015.

[15] Saini, A. \& Martin, K.D., Strategic risk-taking propensity: The role of ethical climate and marketing output control. Journal of Business Ethics, 90, pp. 593-606, 2009.

[16] Lim, E.N.K. \& McCann, B.T., The influence of relative values of outside director stock options on firm strategic risk from a multiagent perspective. Strategic Management Journal, 34, pp. 1568-1590, 2013.

[17] Hiles, A., Enterprise risk management. The Definitive Handbook of Business Continuity Management, 3rd ed., ed. A. Hiles, John Wiley and Sons: Chichester, pp. 4-5, 10-11, 2011.

[18] Herbane, B., The evolution of business continuity management: A historical review of practices and drivers. Business History, 52(6), pp. 978-1002, 2010.

[19] Hiles, A., Marketing protection: A justification for funding of total asset protection programmes? The Definitive Handbook of Business Continuity Management, 3rd ed., ed. A. Hiles, John Wiley and Sons: Chichester, pp. 51-52, 2011.

[20] Torreglosa, J.P., Garcia-Triviño, P., Fernández-Ramirez, L.M. \& Jurado, F., Control strategies for DC networks: A systematic literature review. Renewable and Sustainable Energy Reviews, 58, pp. 319-330, 2016.

[21] Michalski, G., Inventory management optimization as part of operational risk management. Economic Computation and Economic Cybernetics Studies and Research, 43(4), pp. 213-222, 2009.

[22] Michalski, G., Operational risk in current assets investment decisions: Portfolio management approach in accounts receivable. Agricultural Economics - Czech, 54(1), pp. 12-19, 2008.

[23] Hoyt, R.E. \& Liebenberg, A.P., The value of enterprise risk management. The Journal of Risk and Insurance, 78(4), pp. 795-822, 2011.

[24] Gordon, L.A., Loeb, M.P. \& Tseng, C.-Y., Enterprise risk management and firm performance: A contingency perspective. Journal of Accounting and Public Policy, 28, pp. 301-327, 2009.

[25] Garvin, D.A., What does "product quality" really mean? MIT Sloan Management Review, 1, pp. 25-41, 1984.

[26] Reichenbach, P., Rossi, M., Malamud, B.D., Mihir, M. \& Guzzetti, F., A review of statistically-based landslide susceptibility models. Earth-Science Reviews, 180, pp. 60-91, 2018.

[27] Grant, M. \& Booth, A., A typology of reviews: An analysis of 14 review types and associated methodologies. Health Information and Libraries Journal, 26, pp. 91-108, 2009. 